\title{
Serum concentrations of oestradiol and progesterone during the normal oestrous cycle and early pregnancy in the lion (Panthera leo)
}

\author{
Anne M. Schmidt, Leonie A. Nadal, M. J. Schmidt and Nancy B. Beamer* \\ Animal Health Department, Washington Park Zoo, 4001 S.W. Canyon Rd., Portland, Oregon \\ 97221 and *Oregon Regional Primate Research Center, Beaverton, Oregon 97005, U.S.A.
}

\begin{abstract}
Summary. During a 6-month study period weekly serum samples demonstrated 9 oestradiol surges above $14 \mathrm{pg} / \mathrm{ml}$ (range 19-108 pg/ml) among 3 lionesses isolated from male lions. Intervals between peaks ranged from 3 to 8 weeks. Progesterone surges of more than $17 \mathrm{ng} / \mathrm{ml}$ (range $17-282 \mathrm{ng} / \mathrm{ml}$ ) and lasting for 2-6 weeks were recorded after 7 of the oestradiol peaks. Sexual behaviour correlated well with the oestradiol peaks. Except for cornification following oestradiol peaks, there was no obvious vaginal cytology pattern at other times of the cycle. Pregnancy occurred after a 12-h contact with a male during behavioural oestrus. During gestation (108 days) oestradiol values remained low, while progesterone was elevated to $49 \mathrm{ng} / \mathrm{ml}$ within $12 \mathrm{~h}$ after mating, reaching a peak of $143 \mathrm{ng} / \mathrm{ml}$ at the 4 th week, and remaining elevated during the next 2 months.
\end{abstract}

\section{Introduction}

The domestic cat (Felis cattus) is the only felid whose reproductive cycle has been studied in any detail, and hormonal profiles for oestradiol and progesterone during the normal cycle, after a sterile mating and during normal pregnancy have been described (Paape, Shille, Seto \& Stabenfeldt, 1975; Verhage, Beamer \& Brenner, 1976). Behaviour and vaginal cytology have been correlated to produce a picture of the various phases of the oestrous cycle (Michael, 1961). It is known that copulation induces ovulation (Greulich, 1934) and that a sterile mating will produce pseudopregnancy (Paape et al., 1975; Verhage et al., 1976). This information is not available for any other member of the family Felidae.

Basic information on the reproductive cycle of the lion (Panthera leo) is limited to observations of external events. The gestation period (105-111 days) is known from frequent births in captivity (Asdell, 1964). Behavioural oestrous periods have been described (Cooper, 1942; Eaton \& York, 1971; Schaller, 1972), and dioestrous periods have been recorded, but these studies have used copulation as the criterion of oestrus (Sadleir, 1966a, b; Eaton \& York, 1971; Schaller, 1972). If, like the domestic cat, the lion is a reflex ovulator, copulation would affect the length of the cycle (Paape et al., 1975; Verhage et al., 1976). Vaginal smears from lions have been examined (Liche \& Wodzicki, 1939; Rowlands \& Sadleir, 1968), and hormone levels analysed (Seal, Garton, Mather, Gray \& Plotka, 1975; Seal, 1979), but blood samples for oestradiol and progesterone measurements have not been taken serially and hormone concentrations have not been correlated with behaviour and vaginal smear data.

The present study was undertaken to provide information of oestradiol and progesterone concentrations during the oestrous cycle and during a normal pregnancy for the lion and to correlate the changes with behavioural observations and vaginal cytology. 


\section{Materials and Methods}

\section{Animals}

Three mature parous female African lions (Panthera leo) were housed together in the feline building of the Washington Park Zoo, Portland, Oregon, and kept separate from the Zoo's male lions. Enclosures inside the building measured $4.3 \times 2.7 \mathrm{~m}$. On alternate days the lions were allowed outside in a moated trapezoid-shaped enclosure measuring approximately $31 \times 19.5 \times$ $15.3 \mathrm{~m}$. Male lions were housed in adjacent enclosures and alternated in the outside area with the females. This situation allowed olfactory, auditory and limited visual contact, but no physical contact, between males and females. Commercial carnivore diet (Zupreem: Hill's Division Riviana Foods, Topeka, Kansas) was provided 6 times per week.

Because the lionesses had to be immobilized before blood sampling, zoo protocol determined a weekly sampling schedule for the 6-month study period. One lioness exhibited consistent weight loss with repeated immobilizations and the weekly collection of samples from this lioness was terminated after 3 months. The animals were immobilized with ketamine $\mathrm{HCl}$ (Vetalar: Parke Davis, Detroit, Michigan) and xylazine $\mathrm{HCl}$ (Rompun: Haver Lockhart, Shawnee, Kansas) administered intramuscularly via a dart syringe. Blood was collected from the femoral vein, clotted, centrifuged and the serum frozen at $-5^{\circ} \mathrm{C}$ for later analyses.

The lionesses were observed for 45-min periods every day except for the days on which serum samples were collected. Behaviour patterns were recorded in 1-min block periods, then scored by the number of blocks in which they occurred. Behaviours categorized by field (Schaller, 1972) and zoo (Cooper, 1942; Eaton \& York, 1971) researchers as sexual, i.e. lordosis, increased frequency and intensity of rolling, attempts by the oestrous female to move beneath another female, mounting of the oestrous female by another female with copulatory thrusts and neck grip, and a characteristic low growl, were correlated with oestradiol peaks. The frequency of each of these behaviours was tallied to provide a score of sexual behaviour for each week.

Vaginal smears were collected weekly at the same time as the serum samples. A sterile cotton-tipped applicator was inserted for approximately $3.8 \mathrm{~cm}$ and gently rotated in the vagina. The swab was then rotated on a slide and the resulting smear was fixed with alcohol (SprayCyte: Clay Adams, Parsippany, New Jersey). Smears were later stained with Wright's stain and evaluated as described by Herron (1977) in a study of vaginal cytology during phases of the oestrous cycle in the domestic cat.

A pregnancy resulted when Lioness A was allowed physical access to a male lion overnight at the height of a behavioural oestrus. She was separated from the male the following morning when the weekly blood sample and vaginal smear were collected. After 108 days she gave birth to 3 cubs. Weekly blood samples and vaginal smears continued to be collected for the first 2 months of gestation.

\section{Assays}

Oestradiol and progesterone were measured by methods described previously (Verhage et al., 1976) except that the steroids were separated and purified by column chromotography. Crystalline steroid standards, obtained from Steraloids, Inc. (Pawling, New York) were prepared in absolute redistilled ethanol and used without further purification. The antisera to oestradiol and progesterone were purchased from Holly Hills Biologicals, Inc. (Hillsboro, Oregon) and were prepared by injecting rabbits with oestradiol-6-oxime-BSA and progesterone-11 $\alpha$ succinyl-BSA, respectively. The specificity of each antiserum was assessed in this laboratory by incubating $1000 \mathrm{pg}$ of 35 biologically occurring steroids with the same antibody-tracer system used to measure the authentic hormone. No significant cross-reactivity was detected.

Serum samples $(250 \mu \mathrm{l}$ aliquots), reagent blanks, and tritiated steroid recovery samples were 
extracted with ether. The ether extracts were applied to chromatographic columns prepared by placing $1 \mathrm{~g}$ Sephadex LH-20 in a disposable glass column $(1 \times 20 \mathrm{~cm})$ and eluted with a solvent mixture of benzene : hexane :methanol $(62: 20: 13$ by vol.). Purified extracts were then incubated with the appropriate antibody and tritated steroid for quantitation. Correction factors were 1.8 $\pm 0.4 \mathrm{pg}$ blank and $70.6 \pm 1.1 \%$ recovery for the oestradiol assay and $2.3 \pm 0.7 \mathrm{ng}$ blank and $76.8 \pm 0.6 \%$ recovery for the progesterone assay. The limits of sample detection were $5 \mathrm{pg}$ for oestradiol and $50 \mathrm{pg}$ for progesterone; the within-assay coefficients of variation were 5.7 and $9.8 \%$, respectively.

\section{Results}

The serum oestradiol and progesterone concentrations recorded during this study are shown in Text-fig. 1. A total of 9 oestradiol surges suggestive of oestrus (above $14 \mathrm{pg} / \mathrm{ml}$ ) was recorded among the 3 lionesses (range 19-108 pg/ml). Baseline levels of oestradiol were usually extremely

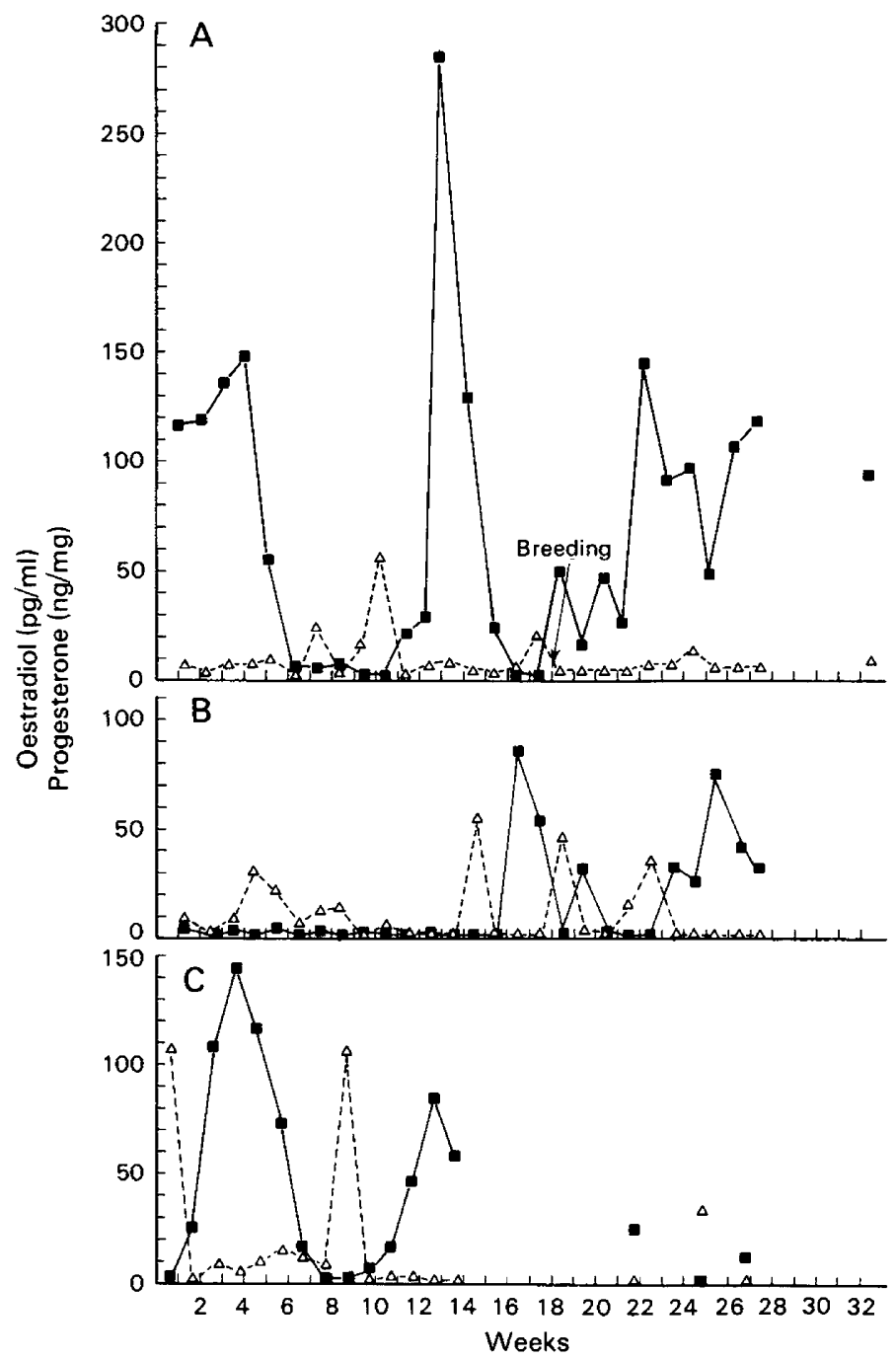

Text-fig. 1. Profiles of oestradiol $(\Delta)$ and progesterone $(\square)$ in 3 individual lionesses. Lioness $A$ became pregnant after mating at Week 18. 
low, at the limits of detection of the assay. Intervals between the peaks varied from 3 to 8 weeks, varying within as well as between animals. Because of the weekly sampling schedule, true peak values were probably missed.

In the lioness which became pregnant an oestradiol surge of $19 \mathrm{pg} / \mathrm{ml}$ was recorded the week before mating. Within $12 \mathrm{~h}$ after mating oestradiol concentration was non-detectable. Values rose slightly to $11 \mathrm{pg} / \mathrm{ml}$ after 6 weeks, declined to non-detectable levels the following week, and then remained at $<5 \mathrm{pg} / \mathrm{ml}$.

A rise in progesterone concentration (range $17-282 \mathrm{ng} / \mathrm{ml}$ ) was detected the week following 7 of the 9 oestradiol surges, but progesterone levels otherwise remained low $(<5 \mathrm{ng} / \mathrm{ml})$. Progesterone rises lasted 2-6 weeks in the non-pregnant animal.

In the pregnant lioness, progesterone values rose from $1.6 \mathrm{ng} / \mathrm{ml}$ during the week before mating to $49 \mathrm{ng} / \mathrm{ml}$ within $12 \mathrm{~h}$ of mating. Progesterone concentration remained elevated (18$144 \mathrm{ng} / \mathrm{ml}$ ) for the 2 months of pregnancy studied, but was declining gradually from the peak at about the 4 th week.

Text-figure 2 shows the score of sexual behaviour correlated with oestradiol values. Correlation of sexual behaviour scores for the week of and the week following the 9 oestradiol surges for all 3 lionesses was statistically significant (point bi-serial $=0.042016, P<0.001$ ), but differences between the lionesses are obvious. Sexual behaviour may not always accompany a hormonal oestrus. In Lioness A sexual behaviour scores fell to non-significant levels during pregnancy.

Vaginal smears showed that cornification occurred consistently after the serum oestradiol rises, but no obvious pattern was detected in the smears collected during other phases of the cycle or during pregnancy.

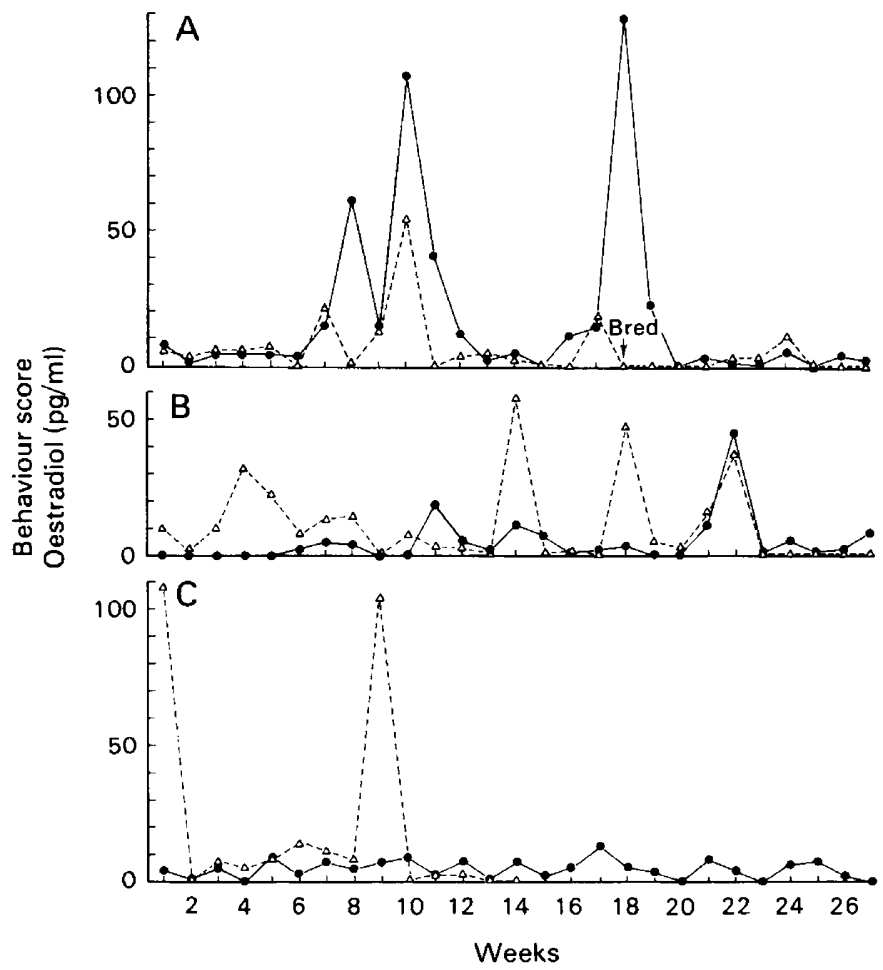

Text-fig. 2. Sexual behaviour scores ( $\odot$, see text) and oestradiol $(\triangle)$ levels in 3 individual lionesses. Lioness A became pregnant after mating at Week 18. 


\section{Discussion}

The oestrogen profile of the African lion followed the pattern exhibited by other mammalian species (Henricks \& Mayer, 1977). In the follicular phase of the oestrous cycle oestrogen secretion surged to a peak value, then fell rapidly to the baseline levels, remaining low throughout the first 2 months of gestation.

The progesterone profile for the non-pregnant lioness was unusual both in the levels and the patterns of progesterone secretion. After 7 of the 9 oestradiol surges, progesterone values increased indicating that ovulation had occurred. Further evidence for the correlation of ovulation with elevated progesterone was obtained a year later, when the ovaries and uteri were removed from each of the 3 lionesses 2 weeks after a behavioural oestrus. Elevated progesterone levels of 16-96 $\mathrm{ng} / \mathrm{ml}$ were measured in serum samples collected at the time of surgery. Examination of the ovaries confirmed that ovulation and luteinization had occurred in all 3 animals. Since, during this study, contact with a male lion was allowed only once and elevated progesterone suggestive of ovulation and luteinization was observed 6 times without mating, copulation may not be required to induce ovulation in the African lion as it is in the domestic cat. Of the 2 cycles with no progesterone phase, one (from Lioness A) was similar to that of a normal non-mated cycle in the domestic cat (Verhage et al., 1976). The other 'anovulatory' cycle (from Lioness B) was unlike any of the other cycles observed, and was assumed to be abnormal. Previous reports of progesterone levels in non-pregnant lions were $<10 \mathrm{ng} / \mathrm{ml}$ for a group of 6 animals with samples collected at random phases of the cycle (Seal et al., 1975), and 50-100 $\mathrm{ng} / \mathrm{ml}$ in lions considered to be possibly pseudopregnant (Seal, 1979).

From the consistency with which the luteal phase was observed, the oestrous cycle of the lion resembled the cycle of the spontaneously ovulating dog more closely than that of the domestic cat in which the luteal phase is not observed without coitus (Paape et al., 1975; Verhage et al., 1976). Progesterone levels were much higher in the lion (up to $282 \mathrm{ng} / \mathrm{ml}$ ) than in the cat (Paape et al., 1975; Verhage et al., 1976) or dog (Smith \& McDonald, 1974; Concannon, Hansel \& Visek, 1975) (both $<40 \mathrm{ng} / \mathrm{ml}$ ). The life-span of a functional corpus luteum in the non-pregnant animals is 36 days in the cat (Verhage et al., 1976) and 80 days in the dog (Smith \& McDonald, 1974; Concannon et al., 1975). In the non-pregnant lion, however, the luteal phase lasted from 2 to 6 weeks, an observation which confirmed the variability previously described for the lion oestrous cycle (Eaton \& York, 1971; Schaller, 1972; Seal et al., 1975). In the single pregnant lion the pattern of progesterone secretion was consistent with the conversion of a corpus luteum of the cycle to one of pregnancy at about the 4th week and then gradually secreting less progesterone.

The behaviour of the lioness in oestrus has been described elsewhere (Cooper, 1942; Eaton \& York, 1971; Schaller, 1972) and is similar to that of the domestic cat. In both felids there are differences in the display and intensity of behaviours between individuals (Michael, 1961).

Vaginal smears collected during this study yielded little information except that, as in other mammals, smears with many cornified cells followed the increases in serum oestradiol. The cell patterns in the vaginal smears could not be used to predict the early phases of the cycle.

We thank Dr Harold Verhage for his excellent support and guidance, and Dr Robert Brenner for examining the ovaries and uteri of the lionesses.

\section{References}

Asdell, S.A. (1964) Patterns of Mammalian Reproduction, 2nd edn. Cornell Univ. Press, Ithaca, New York.
Concannon, P.W., Hansel, W. \& Visek, W.J. (1975) The ovarian cycle of the bitch: plasma estrogen, $\mathrm{LH}$ and progesterone. Biol. Reprod. 13, 112-121. 
Cooper, J.B. (1942) An exploratory study of African lions. Comp. Psychol. Monogr. 17, 1-49.

Eaton, R.L. \& York, W. (1971) Reproductive biology and preliminary observations on mating preferences in a captive lion (Panthera leo) population. Int. Zoo Yrbk 11, 198-202.

Greulich, W.W. (1934) Artificially induced ovulation in the cat (Felis domestica). Anat. Rec. 58, 217-224.

Henricks, D.M. \& Mayer, D.T. (1977) Gonadal hormones and uterine factors. In Reproduction in Domestic Animals, 3rd edn, pp. 79-117. Eds H. H. Cole \& P. R. Cupps. Academic Press, New York.

Herron, M.A. (1977) Feline vaginal cytologic examination. Feline Pract. March, 1977, 36-39.

Liche, H. \& Wodzicki, K. (1939) Vaginal smears and the oestrous cycle of the cat and the lioness. Nature, Lond. 144, 245-246.

Michael, R.P. (1961) Observation upon the sexual behaviour of the domestic cat (Felis cattus L.) under laboratory conditions. Behaviour 18, 1-24.

Paape, S.R., Shille, V.M., Seto, H. \& Stabenfeldt, G.H. (1975) Luteal activity in the pseudopregnant cat. Biol. Reprod. 13, 470-474.

Rowlands, I.W. \& Sadeir, R.M.F.S. (1968) Induction of ovulation in the lion (Panthera leo). J. Reprod. Fert. 16, 105-111.
Sadleir, R.M.F.S. (1966a) Investigation into the reproduction of larger Felidae in captivity. J. Reprod. Fert. 12, 411.

Sadleir, R.M.F.S. (1966b) Notes on reproduction in the larger Felidae. Int. Zoo Yrbk. 6, 184-187.

Schaller, G.B. (1972) The Serengeti Lion. University of Chicago Press.

Seal, U.S. (1979) Endocrine changes associated with reproduction in the lion. Proc. 4th Int. Congr. World's Cats and Sociobiology of Carnivores, Seattle (in press).

Seal, U.S., Garton, R., Mather, L., Gray, C.W. \& Plotka, E.D. (1975) Long-term control of reproduction in female lions (Panthera leo) with implanted contraceptives. AAZV Annual Proceedings 1975, 66-80.

Smith, M.S. \& McDonald, L.E. (1974) Serum levels of luteinizing hormone and progesterone during the estrous cycle, pseudopregnancy and pregnancy in the dog. Endocrinology 94, 404-412.

Verhage, H.G., Beamer, N.B. \& Brenner, R.M. (1976) Plasma levels of estradiol and progesterone in the cat during polyestrus, pregnancy, and pseudopregnancy. Biol. Reprod. 14, 579-585.

Received 17 October 1978 